\title{
Is flow cytometry better in counting malaria pigment-containing leukocytes compared to microscopy? Thomas Hänscheid ${ }^{1,2}$, Rosangela Frita2 ${ }^{2}$ Matthias Längin ${ }^{1,3}$, Peter G Kremsner ${ }^{1,3}$ and Martin P Grobusch*1,4
}

\author{
Address: ${ }^{1}$ Medical Research Unit, Hôpital Albert Schweitzer, Lambaréné, Gabon, ${ }^{2}$ Institute of Molecular Medicine, Faculty of Medicine, Lisbon, \\ Portugal, ${ }^{3}$ Institute of Tropical Medicine, University of Tübingen, Tübingen, Germany and ${ }^{4}$ Infectious Diseases Unit, Division of Clinical \\ Microbiology and Infectious Diseases, National Health Laboratory Service and School of Pathology, Faculty of Health Sciences, University of the \\ Witwatersrand, 7 York Road, Parktown, 2193 Johannesburg, South Africa \\ Email: Thomas Hänscheid - t.hanscheid@fm.ul.pt; Rosangela Frita - r.frita@fm.ul.pt; Matthias Längin - matthias.laengin@gmx.de; \\ Peter G Kremsner - peter.kremsner@uni-tuebingen.de; Martin P Grobusch* - martin.grobusch@wits.ac.za \\ * Corresponding author
}

Published: 16 November 2009

Malaria Journal 2009, 8:255 doi:10.1/86/1475-2875-8-255
Received: 28 July 2009

Accepted: 16 November 2009

This article is available from: http://www.malariajournal.com/content/8/I/255

(C) 2009 Hänscheid et al; licensee BioMed Central Ltd.

This is an Open Access article distributed under the terms of the Creative Commons Attribution License (http://creativecommons.org/licenses/by/2.0), which permits unrestricted use, distribution, and reproduction in any medium, provided the original work is properly cited.

\begin{abstract}
Background: Detection of malaria pigment (or haemozoin; $\mathrm{Hz}$ )-containing leukocytes may have prognostic relevance in malaria; however, studies reported conflicting results, with microscopic counts suggestive of being inaccurate and imprecise.
\end{abstract}

Methods: Numbers of Hz-containing leukocytes from a malaria patient obtained with a flow cytometer counting 50.000 gated events were compared with thin film microscopy as applied under field conditions.

Results: Flow cytometry identified 5.8\% Hz-containing monocytes and $1.8 \% \mathrm{~Hz}$-containing neutrophils. The microscopic examination yielded $10 \%$ and $13 \%$ of $\mathrm{Hz}$-containing monocytes, as well as $0 \%$ and $0.5 \%$ of $\mathrm{Hz}$-containing neutrophils for observers one and two, respectively.

Conclusion: Novel, robust and affordable cytometric methods should be evaluated in the field as they may assist in utilizing $\mathrm{Hz}$-containing cells as clinically useful parameter.

\section{Background}

Malaria continues to be a major health threat to people living in endemic areas, and reliable early identification of patients at particular risk for progressing towards severe disease remains a challenge. During haemoglobin digestion, malaria parasites detoxify the remaining haem into the crystalline malaria pigment, haemozoin $(\mathrm{Hz})$. When the parasites are liberated into the blood stream, the $\mathrm{Hz}$ crystal(s) are also released and removed from the blood by either resident macrophages; or monocytes and granu- locytes in the blood. Thus, the presence of Hz-containing leukocytes in the circulation is an indicator of the presence of Plasmodium spp. However, pigmented monocytes remain in the circulation for a prolonged period of time and may also indicate a recent, successfully treated malaria episode $[1,2]$. Moreover, and particularly so in young children with malaria, accurate and precise determination of Hz-containing leukocytes may serve as a prognostic marker for disease severity and progression $[3,4]$. 
$\mathrm{Hz}$ has interesting physical properties; it is bi-refringent (depolarizing) and paramagnetic. The fact that $\mathrm{Hz}$ can be easily detected using dark field or polarizing microscopy led to some interest in the diagnostic value of pigmented leukocytes. The chance finding that one type of automated haematology analyzers (Cell-Dyn ${ }^{\circledast}$, Abbott, Santa Clara, California) also detects Hz-containing leukocytes during routine full-blood counts has revived this interest and led to a series of studies in endemic and non-endemic areas, as reviewed elsewhere [5].

However, whereas even the finding of a single pigmented leukocyte is highly indicative of malaria, the question arose if the number of Hz-containing leukocytes may harbour useful clinical information. In fact, over the last 20 years a couple of studies reported the quantitative determination of these pigmented leukocytes. Most studies established a highly significant, positive correlation with disease severity although the results from different study sites were highly variable [1,6-9], despite the fact that light microscopy, using Giemsa-stained smears or thick films, was common to all studies. The methodology how the pigmented leukocytes were counted differed largely, as has been pointed out recently [4].

However, many of these studies included a rather small number of patients with severe malaria and even less so fatal cases. A recent study circumvented this problem by pooling the data from six different centers from across Africa [10]. This study included an impressive 26,000 children, which lends power to the authors' conclusion that 'pigmented cells are no useful predictor for disease outcome across Africa'. However, a significant methodological limitation merits further consideration. The pigmented leukocytes were counted in thick films [11]: (i) the number of pigmented monocytes was counted in a total of 200 mononucleated cells; and (ii) the number of Hz-containing granulocytes was obtained by counting them in a total of 200 granulocytes. The median value for pigmented granulocytes was $2 \%$, while for pigmented mononuclear leukocytes it was $4 \%$. However, the most striking result is the rather low percentage of patients who had detec4 pigmented mononuclear leukocytes (63\%) and granulocytes (37\%), as well as the highly significantly discrepant results between the study sites. There were $89 \%$ of patients from Libreville, $81 \%$ from Lambaréné, $70 \%$ from Banjul, $67 \%$ from Kilifi, 54\% from Blantyre and $50 \%$ from Kumasi with pigmented mononuclear leukocytes; there were $70 \%$ of patients from Libreville, $55 \%$ from Lambaréné, $42 \%$ from Kilifi, 40\% from Kumasi, $30 \%$ from Banjul and 16\% from Blantyre with pigmented granulocytes. The odds ratios measuring the associations between pigmented granulocytes and mortality via logistic regression were also very different between the six sites across Africa. The most robust statistical associations were between increased pigmented granulocytes (> 5\%) and fatal outcome, which was significant across all sites when assessed by crude odds ratios of 13.6 for Lambaréné, 12.0 for Blantyre, 3.0 for Kumasi, 2.8 for Banjul, 2.8 for Libreville and 1.6 for Kilifi. Adjusted odds ratios maintained this association in Blantyre, Kumasi and Lambaréné [10].

The problem of determining the accurate number of rare cells by microscopy has an equivalent in hematology: the rather imprecise and inaccurate manual 100 white blood cell (WBC) differential count [12]. Basophils or eosinophils are usually found only a few times during such a 100 WBC differential count. For example, a result of 5\% eosinophils means that only 5 cells of this characteristic were found while observing $100 \mathrm{WBC}$. The $95 \%$ confidence interval (CI) for this $5 \%$ value has been calculated to range from $1 \%$ to $12 \%$ [12]. In fact, it is this limitation, which led to the widespread use of automated haematology analyzers. These instruments analyse around 10,000 cells for a WBC differential, thus reducing the confidence interval to values within decimals of the measured/ detected number of cells; for example, analysing 10,000 cells for the $5 \%$ eosinophil value yields a CI from $4.6 \%$ to $5.4 \%$.

Thus, it is not too surprising that, contrary to the mentioned reports, studies that used flow cytometric methods reported the detection of pigmented leukocytes in most, if not all malaria patients. The various Cell-Dyn ${ }^{\circledR}$ analysers showed a sensitivity for the diagnosis of malaria of 90 $95 \%$ in malaria-endemic regions, including several African countries $[4,13,14]$. This means that $90-95 \%$ of all individuals with malaria did have pigmented monocytes in the peripheral blood that were detectable - a result much higher than in reported studies using microscopy. Moreover, a large number, if not the majority of the patients in the Cell-Dyn ${ }^{\circledast}$ studies had only non-severe malaria; and thus were likely to have considerably lower numbers of pigmented leukocytes. These results are further corroborated by a study that employed image analysis of the Cell-Dyn ${ }^{\circledast}$ on-screen results [4], which showed that $100 \%$ of severe malaria cases had pigmented monocytes and still 94\% of the non-severe malaria cases; while $97 \%$ of severe malaria cases had pigmented granulocytes and $81 \%$ of the non-severe cases. It should be noted that the instrument analysed a mean of 1,364 monocytes and 4,175 granulocytes per sample $(\mathrm{n}=152)$, as compared with only 200 mononucleated cells (including lymphocytes) and 200 granulocytes, as reported in the large multicenter study that used microscopy [10]. Furthermore, during this study, Hz-containing monocytes and $\mathrm{Hz}$-containing granulocytes were determined by the CellDyn ${ }^{\circledast}$ instrument and by manual microscopy count of thick films [4]. Overall, a clear tendency becomes apparent. The total number of Hz-containing cells is underesti- 

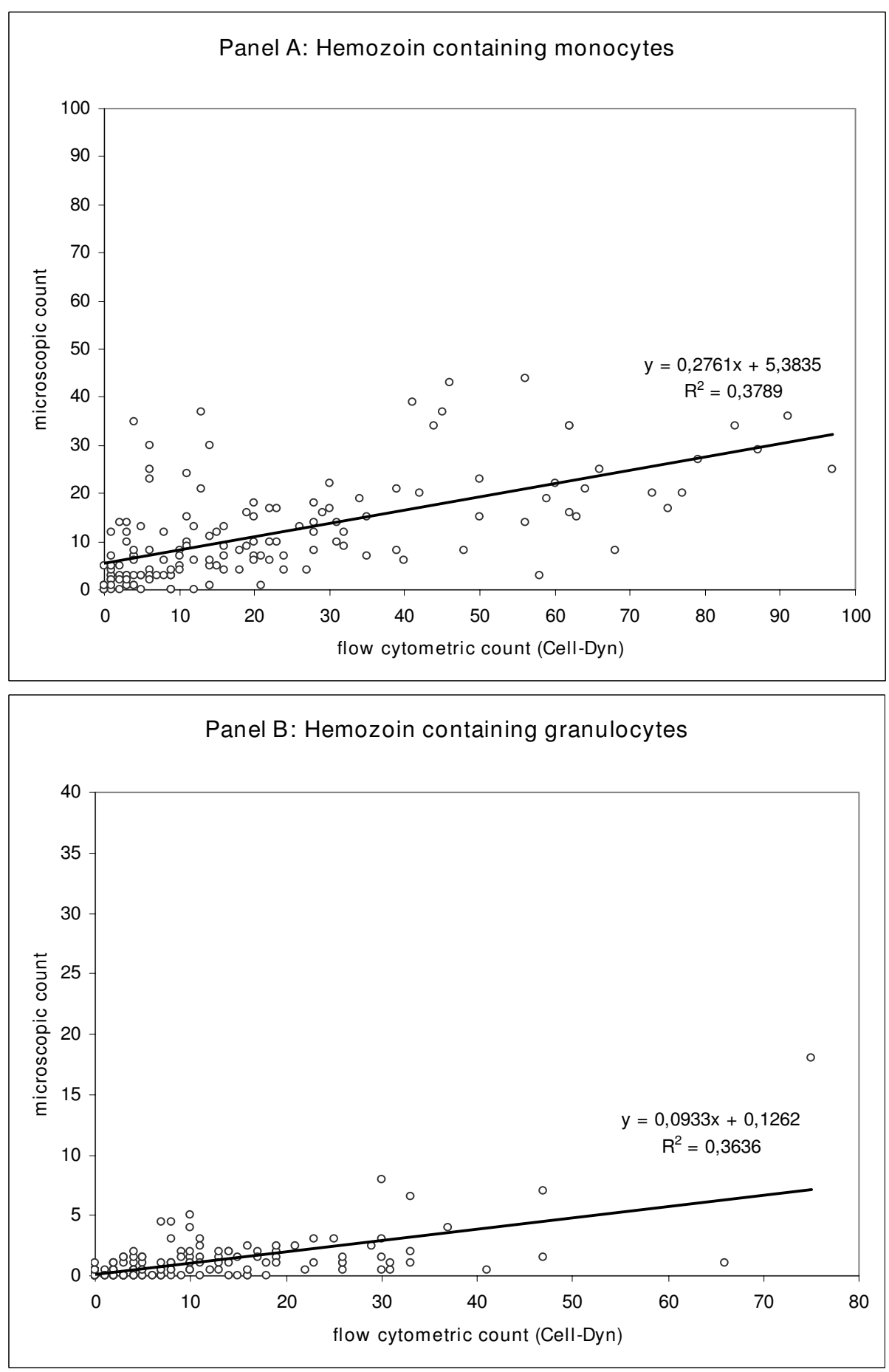

\section{Figure I}

Comparison of flow cytometric and microscopic determination of $\mathrm{Hz}$-containing leukocytes (panel A, monocytes; panel B, granulocytes). I52 samples from malarious patients were used as part of a study on flow cytometric detection of $\mathrm{Hz}$-containing leukocytes [5]. Hz-containing leukocytes were determined by counting 100 monocytes and 200 granulocytes in a thick film, and by image analysis of screenshot from a Cell-Dyn ${ }^{\circledR}$ haematology analyser, as described elsewhere [5]. To allow better scaling in panel A, four outliers were excluded with 173/30, 167/53, 128/33 and II I/50 flow cytometric/microscopic monocyte counts, respectively. 
mated by manual microscopy, especially at higher numbers as determined by flow cytometry (Figure 1). Data interpretation should take into account that the CellDyn ${ }^{\circledast}$ instrument's on-screen results constitute a rather approximate representation of cells analysed. Factors like low screen resolution and representation algorithms may cause a data reduction by a factor of around 5 [4]. Thus, the true flow cytometric count is likely to be several times higher than presented in the figures, increasing the difference even more.

\section{Methods}

Further support for this notion was lent by a simple comparison of a flow cytometric count of $\mathrm{Hz}$-containing leukocytes with thin film microscopy. Leukocytes from a patient with $P$. falciparum malaria ( $0.2 \%$ parasitaemia), were labelled with CD14 (monocytes) and with CD16 (granulocytes) (Becton Dickinson, Franklin Lakes, NJ, USA) and erythrocytes were lysed using a Lysis kit (Partec, Münster, Germany). 50,000 gated events were acquired with a flow cytometer (Cyflow ${ }^{\circledast}$, Partec, Münster, Germany) and $\mathrm{Hz}$ containing leukocytes determined by measurement of Side-Scatter-Depolarization, as described for the Cell-Dyn ${ }^{\otimes}$ instruments [4]. During microscopy, Hzcontaining monocytes were independently counted by two observers as part of a 200-mononuclear-cell count; and $\mathrm{Hz}$-containing neutrophils were counted as part of a 200-polymorph-nuclear cell count, as described recently [10]. Microscopic and flow cytometric counts were then corrected using the Full-Blood-Count result.

\section{Results and Discussion}

Figure 1 depicts the comparison of the flow cytometric and the microscopic determination of Hz-containing leukocytes. Flow cytometry identified $5.8 \% \mathrm{~Hz}$-containing monocytes and $1.8 \% \mathrm{~Hz}$-containing neutrophils. The microscopic examination yielded $10 \%$ and $13 \%$ of $\mathrm{Hz}-$ containing monocytes, as well as $0 \%$ and $0.5 \%$ of Hz-containing neutrophils for observers one and two, respectively.

These results indicate that microscopic counting of $\mathrm{Hz}-$ containing cells is prone to large errors. So, if there is an association of Hz-containing leukocytes and severity of malaria, is there any (clinical) point in counting them? It seems that counting them by microscopy may not yield sufficiently accurate and precise results to turn the number of pigmented leukocytes into a clinically useful marker. However, as flow cytometric methods show, it appears too early to dismiss Hz-containing leukocytes as potentially useful clinical markers of malaria severity. The question is: are there any other, less complicated and expensive methods than flow cytometry to determine these cells with higher accuracy than light-microscopy? Recently a prototype of a low-cost image cytometer has been described that may offer one possible answer to this question [15]. It is currently being developed for detection of Mycobacterium spp. and Plasmodium spp.; and it seems likely that it may also facilitate determination of $\mathrm{Hz}$-containing leukocytes. Whereas rapid diagnostic tests (RDTs) for malaria are of utmost value to assist with establishing a diagnosis of malaria, simple, easily maintainable and affordable flow cytometers adapted to the needs and conditions of rural/semi-rural settings in the South could play an important role in swiftly assisting to predict outcome in malaria, in combination with other much-needed applications in full blood counting, CD4+ counting in HIV/AIDS patients and also TB diagnosis $[16,17]$.

\section{Conclusion}

In conclusion, robust and affordable, purpose-tailored 'no frills' flow cytometric field applications should be tested in the field for diagnostic accuracy and cost effectiveness in comparison with light microscopy as they may assist in overcoming practical limitations of microscopy otherwise so far indispensable for malaria diagnosis.

\section{Competing interests}

The authors declare that they have no competing interests.

\section{Authors' contributions}

TH conceived and designed the study, contributed to the experiments and to data analysis and drafted the paper. RF contributed to the experiments, data analysis and the writing of the paper. ML contributed to the underlying experiments, data interpretation and the writing of the paper. PGK contributed to the design of the study, the data analysis and the writing of the paper. MPG contributed to the design of the study, the data analysis and the writing of the paper. All authors read and approved the final manuscript.

\section{Acknowledgements}

We thank Judith Kammer for excellent technical support.

\section{References}

I. Metzger WG, Mordmüller BG, Kremsner PG: Malaria pigment in leucocytes. Trans R Soc Trop Med Hyg 1995, 89:637-638.

2. Day NP, Pham TD, Phan TL, Dinh XS, Pham PL, Ly VC, Tran TH, Nguyen TH, Bethell DB, Nguyan HP, Tran TH, White NJ: Clearance kinetics of parasites and pigment-containing leukocytes in severe malaria. Blood 1996, 88:4694-4700.

3. Luty AJ, Perkins DJ, Lell B, Schmidt-Ott R, Lehman LG, Luckner D, Greve B, Matousek P, Herbich K, Schmid D, Weinberg JB, Kremsner PG: Low interleukin- 12 activity in severe Plasmodium falciparum malaria. Infect Immun 2000, 68:3909-39I 5.

4. Hänscheid T, Längin M, Lell B, Pötschke $M$, Oyakhirome $S$, Kremsner PG, Grobusch MP: Full blood count and haemozoin-containing leukocytes in children with malaria: diagnostic value and association with disease severity. Malar J 2008, 7:109.

5. Hänscheid T, Egan TJ, Grobusch MP: Haemozoin: from melatonin pigment to drug target, diagnostic tool, and immune modulator. Lancet Infect Dis 2007, 7:675-685.

6. Nguyen PH, Day N, Pram TD, Ferguson DJ, White NJ: Intraleucocytic malaria pigment and prognosis in severe malaria. Trans R Soc Trop Med Hyg 1995, 89:200-204. 
7. Amodu OK, Adeyemo AA, Olumese PE, Gbadegesin RA: Intraleucocytic malaria pigment and clinical severity of malaria in children. Trans R Soc Trop Med Hyg 1998, 92:54-56.

8. Lyke KE, Diallo DA, Dicko A, Kone A, Coulibaly D, Guido A, Cissoko Y, Sangare L, Coulibaly S, Dakouo B, Taylor TE, Doumbo OK, Plowe CV: Association of intraleukocytic Plasmodium falciparum malaria pigment with disease severity, clinical manifestations, and prognosis in severe malaria. Am J Trop Med Hyg 2003, 69:253-259.

9. Mujuzi G, Magambo B, Okech B, Egwang TG: Pigmented monocytes are negative correlates of protection against severe and complicated malaria in Ugandan children. Am J Trop Med Hyg 2006, 74:724-729.

10. Kremsner PG, Valim C, Missinou MA, Olola C, Krishna S, Issifou S, Kombila M, Bwanaisa L, Mithwani S, Newton CR, Agbenyega T, Pinder M, Bojang K, Wypij D, Taylor T: Prognostic value of circulating pigmented cells in African children with malaria. J Infect Dis 2009, 199: I $42-150$.

II. Lell B, Missinou MA, Issifou S, Matsiegui PB, Olola CH, Taylor TE, Kremsner PG: Assessment of a simplified method for counting leukocytic malaria pigment. Am J Trop Med Hyg 2005, 73:588-592.

12. Bain B: Blood cells. A practical guide. Oxford: Blackwell Science; 1995:147-159.

13. De Langen AJ, van Dillen J, de Witte P, Mucheto S, Nagelkerke N, Kager P: Automated detection of malaria pigment: feasibility for malaria diagnosing in an area with seasonal malaria in northern Namibia. Trop Med Int Health 2006, I I:809-8I6.

14. Scott CS, van Zyl D, Ho E, Meyersfeld D, Ruivo L, Mendelow BV, Coetzer TL: Automated detection of malaria-associated intraleukocytic haemozoin by Cell-Dyn CD $\mathbf{4 0 0 0}$ depolarization analysis. Clin Lab Haematol 2003, 25:77-86.

15. Shapiro HM, Perlmutter NG: Killer applications: toward affordable rapid cell-based diagnostics for malaria and tuberculosis. Cytometry B Clin Cytom 2008, 74(SuppI I):SI 52-I64.

16. Sargentini V, Mariotti S, Carrara S, Gagliardi MC, Teloni R, Goletti D, Nisini R: Cytometric detection of antigen-specific IFNgamma/IL-2 secreting cells in the diagnosis of tuberculosis. BMC Infect Dis 2009, 9:99.

17. Sutherland JS, Jeffries DJ, Donkor S, Walther B, Hill PC, Adetifa IM, Adegbola RA, Ota MO: High granulocyte/lymphocyte ratio and paucity of NKT cells defines TB disease in a TB-endemic setting. Tuberculosis (Edinb.) in press.

Publish with Bio Med Central and every scientist can read your work free of charge

"BioMed Central will be the most significant development for disseminating the results of biomedical research in our lifetime. "

Sir Paul Nurse, Cancer Research UK

Your research papers will be:

- available free of charge to the entire biomedical community

- peer reviewed and published immediately upon acceptance

- cited in PubMed and archived on PubMed Central

- yours - you keep the copyright

Submit your manuscript here:

http://www.biomedcentral.com/info/publishing_adv.asp
BioMedcentral 